\title{
Using indigenous knowledge to provide educational services for children with disabilities*
}

\section{Yerli bilgiyi kullanarak engelli çocuklara eğitimsel hizmetler sağlamak}

\section{Article History \\ Received : 01 February 2018 \\ Revised : 13 February 2018}

Accepted : 14 February 2018

Article Type
Review Article

\author{
Maya Kalyanpur ${ }^{1}$
}

\begin{abstract}
Using examples from the author's experiences in Cambodia, India and the US, the paper cautions against the trend of unconditional transfer of policies and practices in inclusive education prevalent in the US, or "first generation inclusive education" countries (Kozleski \& Artiles, 2014) to "second generation inclusive education countries". Differences in political, economic, social and cultural climates make these transfers less applicable in the new contexts and therefore less effective. The paper examines specific challenges relating to implementing inclusive education and in identifying and labeling students, and suggests the need to consider indigenous or local knowledge to develop more appropriate policies and practices.
\end{abstract}

Keywords: International development, inclusive education

Öz: Makalede, yazarın Kamboçya, Hindistan ve ABD'deki deneyimlerinden örnekler kullanarak, ABD'de veya "birinci nesil kapsayıcı eğitim" ülkelerinden (Kozleski \& Artiles, 2014) "ikinci nesil dâhil eğitim ülkelerine", yaygın eğitimde politikaların ve uygulamaların koşulsuz olarak aktarılma eğilimine karşı uyarıda bulunulmaktadır. Siyasi, ekonomik, sosyal ve kültürel iklim farklılıkları, bu transferlerin yeni bağlamlarda uygulanabilirliğini azalttı̆̆ından daha az etkili olmaktadır. Makalede, kapsayıcı eğitimin uygulanması ile öğrencilerin belirlenmesi ve etiketlenmesi ile ilgili spesifik zorluklar incelenmiş ve daha uygun politikalar ve uygulamalar geliştirmesi için yerli veya yerel bilginin dikkate alınması gereğini önerilmektedir.

Anahtar Kelimeler: Uluslararası Gelişim, kapsayıcı eğitim

\footnotetext{
* Presented as “Keynote Speech" at 5th International Early Childhood Education Congress

${ }^{1}$ University of San Diego, mkalyanpur@sandiego.edu
} 


\section{INTRODUCTION}

From 2008 to 2012, I worked as a national advisor in inclusive education with the Ministry of Education, Youth and Sports in Cambodia. I worked with the Department of Teacher Training and the Special Education Office to develop and implement a national policy on inclusive education for children with disabilities. Soon after I started working as the national advisor, I led a training on inclusive education and, as I did not know the language, I conducted my training through a translator. I had worked as a special education teacher in India and then gone to the US to get more training, so I thought I was an expert on inclusive education and particularly in developing countries. I began my training by explaining the difference between the medical model and the social model of disability. The medical model of disability states that the problem of disability is in the individual and the individual needs to be fixed. The social model of disability, on the other hand, recognizes that society creates barriers, for example, through negative attitudes, and it is society that needs to be fixed, not the person. The basic point of this concept is that the medical model is the traditional, old view and we should no longer use it. Instead we should use the social model and understand how we must change society so that we can start including people with disabilities in society. As you can see, the word 'model' here refers to a theory or one way to think of something. However, when I used it in my training, I did not explain this meaning because I assumed everyone would know what the word meant in this context. However, the translator did not understand this. Further, there is no direct translation for the word 'model' in the Cambodian language, so the translator did the best he could and used the word 'system' instead.

Naturally, when the workshop participants heard me telling them that the medical system was bad and we should not use it any more, they could not understand why I was saying this and they said, "But the Cambodian medical system is very good! Why are you saying we shouldn't use doctors anymore?" If they had not told me this, I would have thought they understood what I was trying to tell them and gone back home happy! That is when I realized that when a concept or an idea that is born in Geneva or Paris or London travels all the way to a small village in Cambodia, we have to be very careful to make sure the meaning of the idea does not come out distorted or different from the original meaning. Because of the change in meaning of just one word, the entire meaning of this concept was lost. I also realized that, at the very least, I needed to learn the local language so that I could conduct the trainings myself or follow along as the translator translated. 
I do not know if this story will make sense when it is translated into Turkish but that is exactly my point. I relate this story because I believe it is a good example of how things can get distorted when we do not take the local context into account.

This paper describes some of the trends in international inclusive education and some challenges we are facing in implementation in the US. Since the purpose of learning about what is happening in the US is to be able to apply these policies and practices in other countries, such as Turkey, the paper also argues for the need to understand the contexts in which these policies and practices emerge and the extent to which they can be applied in different contexts. It is perfectly acceptable to take ideas from other countries and to learn from them. We do not have to start from the beginning to figure out what policies should be in place and what practices we should adopt for successful inclusive early childhood education in Turkey. But we have to be careful when we take these ideas and we need to ask ourselves: Do they translate to this new context? Does this policy or practice make sense in the Turkish context just because it is successful in another context, say in the US? How can local or indigenous knowledge help? My hope is that we can see what we can do to avoid some of the same mistakes and challenges the US is facing. I will use examples from my experience in the US as well as in India and Cambodia. I will also draw on other people's research.

\section{Globalization and International Development}

My message is not new in the current context of globalization. Artiles \& Dyson (2009) describe globalization as "the tendency for human activities which occur at places geographically remote from each other nonetheless to interact with each other so that local practices -- in terms, say, of culture, politics or economics - become overlain, or are entirely swept aside by global patterns" and add that "the potential for negative consequences arises... if and when the globalizing tendencies of inclusion lead us - as commentators or advocates, practitioners or policy-makers - to overlook legitimate local differences." Globalization itself is not a new concept. With sea-faring traders in the Middle Ages, food items, in particular, such as the chili or the potato, which were imported to new countries made profound differences in local cuisines. In this period, exchanges were two-way and therefore more equitable.

During the colonial period, however, the process became more one-sided. Historians have provided us a rich body of evidence of the negative consequences of globalization during this period. Take the case of India as a colony of Britain. Around 1750, prior to colonization, India contributed 24\% of the world's Gross Domestic Product. As a result of the transfer of resources from India to Britain, on the eve of India's independence from Britain in 1947. Similarly, the 
transfer of policies from Britain to India resulted in the Macaulay Minute in 1835 which sought to establish an educational system in India that would create "a class of persons Indian in blood and colour, but English in tastes, in opinions, in morals and in intellect" that could serve in the local administrative service.

With the end of colonialism, it was believed that the exchange of ideas would revert to more equitable exchanges. However, that has not prevailed. Instead, as a result of the extreme disparity in wealth which ensued from the colonial trading practices, former colonizing countries and former colonies have been placed along a continuum of development from "developed" countries (the global North) to "developing" or "under-developed" country (the global South). The former colonizing countries have established a template for development that all countries are expected to aspire to. That this level of development was achieved by seizing the wealth of other countries over a period of two hundred years is often overlooked. Equally overlooked is that some of the indicators of development, such as education for all and child labor laws, were conceived and implemented at a much later stage of development, when these countries had the resources to divert towards these endeavors, and not when they were in the impoverished state and growing stages that many developing countries find themselves in currently (Chang, 2003). Instead, the present expectation for globalization is that all the countries whose wealth was depleted through exploitative trading practices now adopt these same indicators of development and achieve them within a much shorter timeframe. If we consider education, for example, the concept of universal primary education emerged in the US in the 1830 s as the need to create within a nation of immigrants a citizenry with similar values, aspirations and language became more compelling. Although non-White children did receive an education, this was both inferior and segregated. By the time of the Civil Rights movement in the 1950s, which demanded equal and inclusive education for all marginalized groups of children, including children with disabilities, the concept of education for all was wellentrenched and the role of child as student was normative.

What complicates the situation further is that the post-colonial conscience, what Cole (2012) calls the "white savior industrial complex", has resulted in the creation of a network of technical and financial assistance from "developed" to "developing". International agencies, such as UNESCO, UNICEF and the World Bank, have attempted to reduce this disparity between developed and developing country by funding professionals in developed countries to transfer their expertise on all aspects of development, including education, to developing countries, on the assumption that policies and practices that were successful in the donor country will be 
equally applicable and successful in the beneficiary country. Accompanying this influx of technical assistance has been monetary assistance, in the form of loans, for projects determined as priorities by donors. For example, the Global Partnership for Education, a multi-donor fund, decided based on research that many children were not able to read and acquire basic literacy fluency despite receiving an education. They dedicated funding for the Early Grade Reading Assessment (EGRA) project towards assessing students on their reading levels and providing alternative means of teaching literacy, which meant that governments in many developing countries received loans to implement EGRA. In order to be able to implement this specific process, governments brought in experts from developed countries as international consultants to introduce EGRA strategies, develop teaching and learning materials, and train local professionals towards building capacity; the remaining dedicated monies was used towards training and implementation costs. Similarly, as part of this technical assistance, the international organizations also established standards for best practice.

\section{International Standards for Disability and Inclusion}

Many of us are familiar with the international framework for inclusive education. For instance, in 1994, the Salamanca Statement was developed to promote inclusive education [quote] "as part of the emerging consensus that children and youth with special educational needs should be included in the educational arrangements made for the majority of children (and) accommodated within a child-centered pedagogy capable of meeting these needs" (UNESCO, 1994, p. 15). In 2000, the World Bank gave us the goal of Education for All by 2015 as part of the Millennium Development Goals. In 2015, this was changed to the Sustainable Development Goals 2025 which go beyond access to education to ensuring quality education for all. In 2004, the World Health Organization developed the International Classification of Functioning, Disability and Health, also known as the ICF, as a template for diagnosis and classification of disability. Most recently, the UNCRPD has outlined best practices for people with disabilities including inclusive education for children with disabilities.

This international framework is reflected in many of the policies for children with disabilities in Turkey. There is the 1983 Law on Children in Need of Special Education, the 1992 Regulation on Educational Practices, the 1997 Decree on Special Education, and the 2000 Ministry of National Education Youth and Sports Regulation which was revised in 2006. These laws and regulations ensure that every individual with special needs has the right to be educated along with their peers in the least restrictive environment, that is, they have the right to inclusive education and their education will be based on individualized education plans or IEPs. The laws 
also ensure that parents have rights with respect to their child's education in early years. Many of these principles, such as parents' rights, and practices, such as the least restrictive environment and IEPs, emerged in the US. I use Kozleski \& Artiles' (2014) terms of "first generation inclusive education" for services in countries such as the US and "second generation inclusive education" for the services in countries like Turkey, India and Cambodia which have adopted the framework of the donor countries. Let us look at some of the challenges we face in the US in implementing them and how we can avoid some of these mistakes when we try to transfer these ideas to other countries. In particular, we focus on two challenges: One, the concept of inclusive education, and, two, perceptions of who is disabled.

\section{The concept of inclusive education.}

What is "first generation inclusive education"? Inclusive education emerges from a historical context of segregated schooling in the US, between the 1890s and 1960s. Although services existed, they existed in the form of institutions where children received mainly custodial care or residential special schools. This parallel system resulted in the creation of a cadre of specialized professionals, such as special education teachers, therapists, and rehabilitation service professionals, and a well-developed infrastructure of curricular and instructional resources. So when the push for inclusive education began in the US in the 1970s, there was an existing body of human and material resources. This made it easier for students with disabilities to start attending mainstream or integrated schools, because their specialized teachers followed them there. The structure for inclusive education which developed at this point in the 1970s, first called mainstreaming, then integration and finally inclusion was this: Students with disabilities go to general education schools and receive support services there. Some students receive their education in special education classrooms where they spend the entire school day in a separate classroom with a special education teacher. Some students receive their education in the general education classrooms and leave for a few hours of the school to go to what is called a resource room, where a special education teacher helps them to understand better what they have learnt in the general education classroom. Some students spend their whole day in the general education classroom, and the special education teacher or assistant will work with them sometimes together with the general education teacher or separately in small groups or individually to help the student understand better what is being taught in the general education classroom. Inclusion did not make the role of a special education teacher obsolete, as was originally feared, but more needed than ever. 
As we see from the international policy framework on inclusive education, the concept of inclusive education moved to other parts of the world besides the US and Western Europe only in the 1990s. The concept was based on the understanding of how inclusion was being practiced in the US and Western Europe, with students with disabilities going to school in general education schools and receiving support services there. However, second generation inclusive education is much more problematic (Kalyanpur, 2008a). For one, the standard of Education For All is itself being newly implemented in many countries, which are still struggling to achieve hundred percent enrollment and retention rates, and the concept of access to education being the norm for all children is relatively new. Large proportions of marginalized groups, like poor children or street children, continue to be out of school. For another, making education accessible for all school-age children means increasing the number of teachers, but the supply of trained teachers has not kept up with the sudden increase in demand. With few trained professionals and even fewer material resources, general education teachers have very large class sizes. In primary classrooms in Cambodia, for instance, there are over 60 students in one class. As a result, general education teachers are extremely reluctant to accept students with disabilities. In fact, they are more likely to be willing to include other groups of marginalized children, like poor children or street children because they do not require any extensive accommodations. A World Bank study (2011) found that, in efforts to reach out to all out-ofschool children, students with visible disabilities are the last and least likely to be included. The lack of infrastructure of special education teachers and specialized materials has added to the burden of implementation of second generation inclusive education.

\section{Challenges in implementing inclusive education.}

Even within the US, the parallel system of special education moving into an inclusive system has created a big challenge as it struggles to implement inclusive education. This is because most general education teachers do not know how to teach children with disabilities and most special education teachers do not know what to teach general education students. Many general education teachers are quick to say that a child needs special education because the child is disruptive in class or receiving low grades, rather than taking the time to find out what the problem might be or teaching the child in different ways. They belong to the traditional view of the medical model, believing that it is the child who needs to be fixed. They are also products of a systemic problem of traditional teacher education models with separate tracks for general and special education pre-service training. Now slowly teacher preparation programs are moving towards blended programs. For instance, the teacher education department at the 
University of San Diego is in the process of developing a graduate program in education where our teacher candidates will take blended courses in special and general education and will graduate with both general and special education credentials so they can teach all students. Research informs us that eighty percent of all children with mild to moderate disabilities can be taught this way; fifteen percent might need some additional support which can be provided in small groups or within the school and just five percent will need special education services (Friend \& Bursuck, 2014).

\section{Considering alternative solutions through indigenous knowledge of inclusion.}

If we build on local knowledge, second generation inclusive education can also develop creative solutions. This can be on a systemic, national level or on an individual, school-based level. Many countries have chosen to create special schools where students with disabilities can receive a quality education. In India, for instance, inclusive education means education for all historically out-of-school children, not just children with disabilities (Kalyanpur \& Misra, 2011; Kalyanpur, 2008a). Even special schools are seen as inclusive schooling, the rationale being that any schooling is better than no schooling at all. Initially most special schools were established through parent associations and NGOs. The government entered the arena later, approving these private special schools and also investing in government-run special schools, called inclusive schools, for different types of disabilities. It established national training centers specializing in various disability categories to create a corpus of trained professionals in special education and rehabilitation services. More recently, it has begun to fund support services for students with disabilities, including training for teachers, in regular government schools and offer state aid to private regular schools willing to enroll students with disabilities as well. The teachers receive training from special schools, which serve as resource and training centers, to learn to teach all students. Although these different structures still do not provide comprehensive educational coverage for students with disabilities, they offer organic responses to the local situation of very limited human and material resources.

Implementing second generation inclusive education on a school-based level also requires an understanding of local cultural factors. For instance, in Cambodia, my Ministry of Education colleagues and I helped to facilitate a collaborative effort between the special schools and the government primary school to provide inclusive education for students with disabilities (Kalyanpur, 2014; Kalyanpur, 2011). We conducted a situation analysis so I could better understand the local context and my colleagues could identify both barriers and strengths in the culture that would facilitate better implementation of inclusive education. We visited schools 
and interviewed policy makers, provincial and district education officers, teachers, school directors, parents, children with and without disabilities and community members. I found that Cambodia had very few services for children with disabilities. The government had started a project for inclusive education in one school, but after the third year, the project ended for lack of support. When I started as advisor, there was one school for blind children and one for deaf children, both run by the same non-governmental organization or NGO. There was one school for children with physical and mobility impairments and one for children with severe intellectual disabilities run by separate NGOs. All were located in the capital city and were residential. Because there were no other services, children were coming from all over the country to live in these schools. When we interviewed one 10 -year-old boy who was blind at his school, he cried the whole time because he was missing home so much. Family is important within the Cambodian culture and it seemed as if we were punishing children because they had a disability.

The NGOs which ran the special schools were keen to implement inclusive education and move many of their students to local government schools. One arrangement the NGO for blind students worked out was that, after the third grade, the students would attend the local government school and then return to the NGO school in the afternoon to review the same lessons. The NGO for students with intellectual disabilities arranged to be allotted one classroom in a regular school, so that some of their students could attend regular school, albeit in a self-contained classroom. Although teachers in urban areas were willing to take students with disabilities, the NGOs knew the teachers would not want them without training and supports. Even with training, the teachers were reluctant to take students who needed too many curricular modifications. Based on this analysis, we realized that, one, if we wanted a sustainable program, the students should be living locally and not have to leave home to go to school, and two, schools and particularly teachers would need to continue to receive support.

Together the Ministry and NGO found a school located close to the NGO which served blind children where the school director and teachers were willing to take in some students and we decided to start with students with low vision, since they required fewer curricular modifications than blind students. Together with the provincial teacher training college and the NGO, we developed a week long training module for the teachers in this school to understand the specific needs of low vision students. Over the summer, the NGO visited homes in the neighborhood to identify students with low vision, and at the beginning of the academic year, these students were placed in general education classrooms with low vision glasses and assistive 
devices, such as a magnifying glass and bookstand, provided by the NGO. With the help of these devices, the students could learn independently or with some help from their classmates. Plus, these students could live at home and go to school with their neighborhood friends while the teachers continued to get support from the NGO and the Teacher Training College. Because we applied our understanding of the local needs and strengths, this collaboration between the special school and the government school was a successful first step towards inclusive education.

\section{The concept of labeling and identification.}

The International Classification of Functioning and Disability developed by the World Health Organization provides a universal instrument for identifying, classifying and labeling people with disabilities. However, it has been criticized for being embedded in the medical model and for not considering differences in local contexts. Research shows that, in some cultures, certain conditions are not seen as disabilities (Kalyanpur \& Harry, 2012). For example, because the son of an Asian-American family in the US had a club foot condition, which prevented him from running fast and participating in many physical activities with his friends, the AngloAmerican preschool social workers told the parents that they should do something about his disability: a simple surgery could make him "normal". The parents, however, did not think that their son had a disability. The social workers took legal action against the family, saying they were neglecting their son and that they did not want their son to be 'normal'. The parents explained that to the judge that their son's club foot was a special sign of grace he had inherited from an ancestor who had probably died in a war because his foot was wounded. The boy's foot condition brought harmony to his community, so the family did not want to break this harmony by giving him the surgery. The rights of the community were more important that the boy's rights.

Similarly, categories like learning disabilities and behavior disorders have been criticized as being socially constructed (Duhaney, 2014; Harry, 2014). This is because they are "soft" disability categories that do not have any specific biological etiology, and their identification is based primarily on perceptions. Research has shown that problems in the assessment process often leads to the over-representation of minority students in special education. The process by which students are identified as being learning disabled or behavior disordered tends to be subjective. In fact, we refer to them as the "soft" disability categories because there is no hard evidence to prove the existence of these conditions; the decision is based entirely on 
perceptions, on how people choose to see a person and what skills and behaviors are deemed important in a culture.

For example, before Education For All, it was not assumed that everybody would be able to read, and in fact many adults never learned to read. Now we assume that everybody will learn to read, and so if someone has difficulty learning to read, we call them 'learning disabled'. In the same context, what is appropriate behavior is culturally defined. In my Indian culture, it is not considered rude to interrupt a person who is speaking and we do it, consciously and unconsciously all the time. Even after living in the US for so many years, I have to be so careful to stop myself from interrupting another person because it is considered extremely inappropriate in America! How close you stand to another person, how you show respect and deference and to whom, who eats first and last at family gatherings, all these behaviors are culturally defined. In her research, Delpit (2006) describes how an Anglo-American preschool teacher thought her African-American student was being defiant and might have a behavior disorder because he would not follow directions when, at the end of a cutting and pasting activity, she would tell him "The scissors go in the box." But when Delpit asked the boy's mother if he was being defiant, the mother immediately explained that if she wanted the boy to put the scissors away, she would say directly, "Put the scissors away." The boy was not following the teacher's directions because he didn't understand that the teacher was telling him to do something; he just thought she was giving him information that the scissors went in the box. Because of a difference in communication style between home and school that the teacher did not take into account, the boy might have ended up being labeled behavior disordered.

\section{Challenges in implementation of labeling and identification.}

One of the biggest challenges the US faces in special education is the problem of minority overrepresentation: that even though certain groups of students, such as African-Americans, Hispanic-Americans and Native Americans, are in a minority in the total population of students, they are in the majority in special education (Harry, 2014). African American students make up only 16 percent of the student population, but make up 32 percent of the students in special education. The numbers are similar for Hispanic students. In gifted education, the numbers are inversed - white students make up more than twice the percentage of students in gifted programs than in regular education programs. This is problematic because once students are receiving special education services, one, they tend to remain in special education classes (Harry, 2014); two, they are likely to encounter a limited, less rigorous curriculum which can 
lead to reduced opportunities after school such as not going to college; and, three, disabled students are often stigmatized.

Research has shown that the assessment process often leads to the over-representation of minority students in special education because it tends to be subjective (Duhaney, 2014). There are two aspects to this subjectivity. One, assessments make assumptions about universal developmental milestones (Kalyanpur, 2008b). The first assumption is that they occur at the same time for all children, such as turning over at three months, sitting up at six, etc. However, certain cultural practices may result in earlier acquisition of developmental milestones. For example, before the days of disposable diapers in India, researchers found that toilet training occurred in children earlier in India than in the US, even as early as six months (Kalyanpur, 1996). This does not mean that babies in India are more developmentally advanced than babies in the US but that mothers had an incentive to introduce the conditional reflex that leads to bladder control earlier to reduce washing loads! Similarly, another researcher found that the practice in India of placing the baby on the lap and rocking them gently back and forth to burp them accelerated their neck control. So all milestones do not occur at the same time for all children. A second assumption is that developmental milestones are the same universally (Scherzer, 2009). However, research has shown that mothers may identify other events in their child's life as a developmental milestone: In Cambodia, mothers spoke about "bat phneak", literally translated to "opening of the eyes" of their one-month-old babies. Navajo mothers identified their baby's first smile as a developmental milestone. In India, a baby's first meal of solid food is often seen as a developmental milestone.

Another aspect of the subjectivity of the assessment process relates to the myth of the norm as measured by the bell curve. When we measure an indicator as tangible as people's height, for instance, the height of 5,000 20-year-old Turkish women, we would find that most women (about 50\%) fall within a range close to $161.4 \mathrm{~cm}$, which is the average or norm, while $25 \%$ will be over one standard deviation over and $25 \%$ will be one standard deviation below. This spread is represented graphically as a bell curve. The bell curve is also used to represent IQ scores, whereby it is understood that about $50 \%$ of all people have average IQ scores of around 100 and 25\% have IQ scores one standard deviation below and 25\% have IQ scores one standard deviation above the norm. However, IQ is primarily a psychometric construct, that is, the concept of IQ is constructed from our assumption of what people at different ages should be able to do and know and IQ tests are then in turn assumed to measure this construct. This makes 
both the construct of IQ problematic as well as its measurement through norm-referenced IQ tests.

The most common IQ test used to assess school students is the Wechsler Intelligence Scale for Children (WISC). This is an individually administered intelligence test for children between the ages of 6 and 16 inclusive. It is popular because it can be completed without reading or writing and so it is assumed that it is universally applicable. However, there are several problems associated with IQ tests. These tests are standardized on certain populations called the "norming group" but most often administered to children who were not included in this group. For instance, the WISC is standardized on a population of children in the US but is being administered to children, say, in India and in Turkey. Even within the US, minority populations tend to be under-represented within the norming group, although the tests are most often administered to them. In some situations, IQ tests are modified to be more culturally appropriate, but these modifications do not relate to the norming group, but to the content of the test items. For instance, the original question, "who discovered America?" which permitted the answer "Columbus" as the only accurate response has been recently modified to allow alternative responses such as "Vespucci"; however, it still does not allow the possibility that to many Native American students, America was never "discovered" or that this knowledge may not, in the first place, be universal. Similarly, in India, the original question "Who was the first president of America?" might be modified to "Who was the first president of India?" This does not take into account the fact that with India's parliamentary system, children would be more likely to know who the first prime minister is, not the president.

\section{Considering alternative solutions through indigenous knowledge of labeling.}

Given the stigma that is often attached to disability, there are advantages in not categorizing or labelling students. In the 1980s, the Indian government made a concerted effort to move away from the use of derogatory commonly used words for describing people with disabilities to the less well-known and therefore more value-neutral term of "viklang". Then, in 2016, the Department of Empowerment of Disability Affairs decided to substitute this term, which they claimed now had negative connotations, with the word "divyang" or 'divine body' on the grounds that "these are people who have a limb or several limbs with divine powers" (Sharma, 2016). The move sparked a debate among disability rights advocates and activists. Some argued that the new term suggested a throwback to the stereotype of "supercrip", while others noted that "more important than terminology was the government's commitment to the well-being of people with disabilities and ensuring that the Rights of Persons with Disabilities Bill be passed" 
(Sharma, 2016). The issue of the necessity of labeling for purposes of policy planning and service provision come into question: To what extent do prevalence studies provide true demographic data that reflected local perceptions of disability? To what extent are disability certificates truly useful in determining the level of supports an individual might need? For instance, an evaluation of the Janshala Schools or EFA program in India found that many teachers and other members of the community resisted the idea of labelling children and separating them on that basis because they recognized that ability grouping created a sense of discrimination and led to social conflicts (Gandhe, 2004, cited in Kalyanpur, 2008a).

An alternative approach to assessment, called dynamic assessment, developed separately by Feuerstein in Israel and Vygotsky in the former USSR recognizes that learning is not static as measured through IQ and other norm-referenced tests. The idea is to identify a child's learning potential, to gauge how quickly and what they have learnt and then re-teach if they need. In this format, the child is asked to perform a basic task which involves the skill being tested. If the child is not able to perform the task, the child is taught in steps how the task is to be performed. The child is then given the same task again and observed (you can say tested) to see how much of the child is able to complete, in other words, how much has the children been able to learn. This idea of scaffolded learning is imbedded in a new approach to assessing students called Response to Intervention that is being implemented in the US. It is being used to check on the progress of students, often on a daily basis, on small tasks related to reading and math to assess what they have learned after being taught the task. By providing this very focused, direct instruction based on the child's performance at the point when the child begins to show signs of struggling academically, about $80 \%$ of children have been shown to respond to intervention and come up to grade level. It has proved to be an effective approach to preempt children ending up in special education and avoid labeling.

Unfortunately, as these efforts to avoid labeling in the US are relatively new, they have not been able to reverse the trend towards labeling in other countries. In Cambodia, for instance, a prevalence study was conducted with considerable international monetary and technical aid to identify prevalence rates for internationally defined categories of disability that did not reflect local perceptions, despite protests from national stakeholders (Kalyanpur, 2014). When an international aid agency did decide to involve local stakeholders in reconfiguring these categories of disability to reflect local lived realities, no families or people with disabilities who were not already involved in a professional capacity were included in the consultative process 
(Kalyanpur, 2016). Terms like autism and learning disability are being imported to developing countries which are now seeing exponential increases in the incidence of these categories.

We are beginning to see this phenomenon develop in India, too (Kalyanpur, 2015). Economic liberalization leading to improved access to education in India and therefore increased competitiveness in schools is also leading to a growing number of students who are being labeled as learning disabled because they may be struggling academically. The Indian government has been unable to respond to the need for schooling by building sufficient schools and populating them with trained teachers. In response, the private, in some cases non-profit, sector has stepped in and has created a tiered educational system. At the top is a tier of schools that charge very high fees and cater primarily to affluent families; the medium of instruction is primarily English giving its students a tremendous advantage in the global market. Constituting two percent of their population, they can aspire to enter the top ranked colleges and universities, because of their language proficiency, both nationally and internationally. The next tier of schools offer instruction in regional languages, which allow students to continue in state level higher education institutions. Some of the regional-language schools also offer parallel tracks where science and mathematics is taught in English; although the intention is that second-tier students would also have access to top-tier institutions, the lower level of English proficiency limits their options. The third tier of schools attracts students from low socio-economic backgrounds because they charge low fees and offer English as the medium of instruction; while ordinarily these students would have enrolled in government schools which are free, the allure of receiving an education in English, which the government schools would not provide, overrides the financial burden for families.

What is troubling is that this system of low-fee paying English medium schools is failing students from low socio-economic backgrounds and non-English-speaking backgrounds. Similar to the US, many are being labeled learning disabled, not because they have a cognitive delay but because they have a language difference. Tests to identify students are based on models used in the US, such as the WISC IQ test and the Woodcock-Johnson achievement test, which have been minimally modified in content, not in standardization of the norming group, to Indian populations. Although RTI has been introduced in India, it is too sparse to make a difference yet and does not address the concern about imposing an additional burden on general education teachers. 


\section{CONCLUSION}

In conclusion, we may certainly learn from other countries but let us do it wisely, recognizing what doesn't work there, and what won't work here instead of bringing everything in indiscriminately. We need to investigate and delve deeply into ourselves and identify our own strengths and cultural values. Our biggest strength is the advantage we have over first generation IE countries of time, of being behind and the second-generation so we can learn from their mistakes instead of repeating them. Policies and practices based on indigenous knowledge, on information that is grounded within the community, are much more likely to flourish precisely because they are homegrown.

\section{REFERENCES}

Balc1. A. (2007). Sosyal bilimlerde araştırma: Yöntem, 1.5nik ve ilkeler. Ankara: Pegema Yayıncilik.

Artiles, A., \& Dyson, A. (2009). Inclusive education in the globalization age: The promise of comparative cultural-historical analysis. In D. Mitchell (Ed.), Contextualizing inclusive education: Evaluating old and new historical perspectives (pp. 37-62). London: Routledge.

Chang, H. (2003). Kicking away the ladder: Development strategy in historical perspective. London: Anthem Press

Cole, T. (2012). The white savior industrial complex. The Atlantic. Retrieved from http:/www.theatlantic.com/international/archive/2012/03/the-white-savior-industrialcomplex/254843/

Delpit, L (2006). Other people's children: Cultural conflict in the classroom. W. W. Norton: New York.

Duhaney, L.M.G. (2014). Disproportionate representation in special education: A persistent stain on the field. In F. E. Obiakor \& A. F. Rotatori (Eds.), Contemporary perspectives in special education: Multicultural education for learners with special needs in the $21 \mathrm{st}$ century (pp. 15-40). Charlotte, NC: Information Age Publishing.

Friend, M., Bursuck, W. (2014). Including students with special needs: A practical guide for classroom teachers. 7th Edition. Upper Saddle River, New Jersey: Pearson

Harry, B. (2014). The disproportionate placement of ethnic minorities in special education. In L. Florian (Ed.). The SAGE Handbook of special education, volume 1, 2nd ed. (pp. 7395). Thousand Oaks, CA: Sage.

Kalyanpur, M. (2017). Cultural reciprocity in home-school collaboration within international contexts. In E. C. Lopez, S. G. Nahari, \& S. L. Proctor (Eds.) The Handbook of Multicultural School Psychology. New York: Routledge.

Kalyanpur, M. (2016). Inclusive education policies and practices in the context of international development: Lessons from Cambodia. In Andreas Köpfer \& Christian Brüggemann (Eds.) Special Issue of the Journal of International Education Research and Development Pedagogy, 3, 16-21. 
Kalyanpur, M. (2015). Mind the gap: The evolution of special education policy and practice in India in the context of globalization. In S. Rao \& M. Kalyanpur (Eds.) South Asia and Disability Studies: Redefining boundaries and extending horizons. (pp. 49-72) New York: Peter Lang.

Kalyanpur, M. (2014). Distortions and dichotomies in inclusive education for children with disabilities in Cambodia in the context of globalization and international development. International Journal of Disability, Development and Education, 61(1), p. 80-94. 15p. DOI: 10.1080/1034912X.2014.878546.

Kalyanpur, M. (2011). Paradigm and paradox: Education For All and the inclusion of children with disabilities in Cambodia. International Journal on Inclusive Education, 1-19, DOI:10.1080/13603116.2011.555069.

Kalyanpur, M. (2008a). Equality, quality and quantity: Challenges in inclusive education policy and service provision in India. International Journal of Inclusive Education, 12(3), 243263.

Kalyanpur, M. (2008b). The paradox of majority under-representation in special education in India: Constructions of difference in a developing country. Journal of Special Education, 42(1), 55-64.

Kalyanpur, M. (1996). The influence of western special education on community-based services in India. Disability \& Society, 11(2), 249-270.

Kalyanpur, M. \& Harry, B. (2012). Cultural reciprocity in special education: Building reciprocal family-professional relationships. Baltimore: Brookes.

Kalyanpur, M. \& Misra, A. (2011). Facing the challenge of inclusion in India. In K. Mazurek \& M. Winzer, (Eds.) International practices in special education: Debates and challenges. (pp. 193-216). Gallaudet University Press.

Kozleski, E., Artiles, A., \& Waitoller, F. (2014). Equity in inclusive education: A cultural historical comparative perspective. L. Florian (Ed.). The SAGE Handbook of special education, volume 1, 2nd ed. (pp. 231-250). Thousand Oaks, CA: Sage. DOI: $10.4135 / 9781446282236 . n 16$

Scherzer, A. L. (2009). Experience in Cambodia with the use of a culturally relevant developmental milestone chart for children in low- and middle-income countries. Journal of Policy and Practice in Intellectual Disabilities, 6, 287-292.

Sharma, A. (Oct 22, 2016). Department of Empowerment of Disability Affairs to incorporate the word 'Divyang' in Hindi and English names. Economic Times. Retrieved from: https://economictimes.indiatimes.com/news/politics-and-nation/department-ofempowerment-of-disability-affairs-to-incorporate-the-word-divyang-in-hindi-andenglish-names/articleshow/52408370.cms

World Health Organization (WHO) \& World Bank. (2011). World report on disability. Washington, DC: Author. 